BMJ Open Diabetes Research \& Care

\title{
Changes in insulin sensitivity and insulin secretion during pregnancy and post partum in women with gestational diabetes
}

\author{
Gitte Oeskov Skajaa (D) , ${ }^{1}$ Jens Fuglsang (D) , ${ }^{1}$ Sine Knorr, ${ }^{2}$ Niels Møller, ${ }^{3}$ \\ Per Ovesen, ${ }^{1}$ Ulla Kampmann ${ }^{2}$
}

To cite: Skajaa GO, Fuglsang J, Knorr S, et al. Changes in insulin sensitivity and insulin secretion during pregnancy and post partum in women with gestational diabetes. BMJ Open Diab Res Care 2020;8:e001728. doi:10.1136/ bmjdrc-2020-001728

Received 26 June 2020 Revised 23 August 2020 Accepted 14 September 2020

Check for updates

\section{(C) Author(s) (or their} employer(s)) 2020. Re-use permitted under CC BY-NC. No commercial re-use. See rights and permissions. Published by BMJ.

${ }^{1}$ Department of Obstetrics and Gynecology, Aarhus University Hospital, Aarhus, Denmark

${ }^{2}$ Steno Diabetes Center Aarhus, Aarhus University Hospital,

Aarhus, Denmark

${ }^{3}$ Medical Research Laboratories, Department of Clinical Medicine, Aarhus University, Aarhus, Denmark

Correspondence to Dr Gitte Oeskov Skajaa; gitteoskajaa@clin.au.dk

\section{ABSTRACT}

Introduction The metabolic abnormalities underlying gestational diabetes mellitus (GDM) include increased insulin resistance and beta cell defects, but it is essential to clarify how insulin resistance and insulin secretion develop post partum in order to decide when and how to screen for type 2 diabetes. The purpose of the present study was to characterize and compare changes in insulin sensitivity, insulin secretion and hormonal status around parturition and 6 months post partum in women with gestational diabetes.

Research design and methods A longitudinal experimental study was performed at Aarhus University Hospital, Denmark. Eight women with GDM were examined at three identical visits: in late pregnancy (LP) between gestational age $34+0$ and $36+6$, early post partum (EPP) between 12 and 34 days post partum, and late post partum (LPP) 6 months post partum. An intravenous glucose tolerance test was performed, followed by a hyperinsulinemic euglycemic clamp. Blood samples were collected to assess metabolic, hormonal and inflammatory markers at each visit.

Results First and second phase insulin secretion and C-peptide concentrations were higher in late pregnancy than post partum $(p<0.001)$. Insulin sensitivity index (ISI) was different at all three visits: $\mathrm{ISI}_{\mathrm{LP}}=0.03 \pm 0.004$, $I S I_{\text {EPP }}=0.09 \pm 0.008$ and $\left.I S I_{\text {LPP }}=0.07 \pm 0.008\right)(p<0.001)$. Also, significant changes in lipids, leptin, glucagon, growth hormone and insulin-like growth factor-1 were seen when comparing the visits.

Conclusions Insulin sensitivity improves immediately after delivery in women with GDM but seems to deteriorate within the first 6 months post partum. Our findings underline the importance of having an increased awareness of the profound risk of developing type 2 diabetes after GDM.

Trial registration number NCT02770079.

\section{INTRODUCTION}

Insulin sensitivity decreases by $50 \%-60 \%$ both in normal pregnancy and in pregnancies complicated by gestational diabetes mellitus (GDM). ${ }^{12}$ However, women who develop GDM have a decreased peripheral insulin sensitivity present already before conception ${ }^{3}$

\section{Significance of this study}

What is already known about this subject?

- Insulin sensitivity improves rapidly after parturition in women with gestational diabetes.

- The risk of developing type 2 diabetes, in the years after a pregnancy with gestational diabetes, is substantial.

What are the new findings?

- Insulin sensitivity improves immediately after delivery in women with GDM but seems to start deteriorating within the first 6 months post partum.

- Insulin secretion was highest in late pregnancy compared to 2 weeks and 6 months post partum.

- Leptin levels decreased shortly after delivery but was increased again 6 months post partum.

How might these results change the focus of research or clinical practice?

- This underlines the importance of increased focus on the profound risk of developing type 2 diabetes after GDM and warrants initiatives shortly after delivery including dietary, lifestyle and pharmacological interventions aimed at preventing or delaying type 2 diabetes.

and a beta cell dysfunction that cannot meet the increased insulin demands during pregnancy, resulting in hyperglycemia. ${ }^{1}$ The risk of developing type 2 diabetes, in the years after a pregnancy with GDM, is substantial. A meta-analysis showed a relative risk of 7.43 in women with GDM compared with those who had a normoglycemic pregnancy, ${ }^{4}$ and a Danish study has shown that $40 \%$ of women with GDM developed type 2 diabetes within 9.8 years after their index pregnancy. ${ }^{5}$ Most countries recommend that women with a history of GDM are screened for type 2 diabetes by an oral glucose tolerance test (OGTT) 4-12 weeks post partum and by measuring a hemoglobin A1c (HbAlc) every 1-3 years post 
partum. ${ }^{6}$ However, compliance in completing the OGTT post partum is poor and novel approaches in screening are in the process of being evaluated. ${ }^{78}$ Several studies have been performed aiming to describe glucose metabolism post partum, ${ }^{9-12}$ but the studies have either used surrogate measures for insulin sensitivity and insulin secretion $^{9}$ or assessed insulin sensitivity using the gold standard method, hyperinsulinemic euglycemic clamp (HEC), either a few days after delivery or 1 year post partum. ${ }^{10-12}$

The scope of the current study was therefore to assess changes in insulin secretion and insulin sensitivity in women with GDM late in pregnancy, 2 weeks and 6 months after delivery, using the gold standard method: an intravenous glucose tolerance test (IVGTT) followed by a HEC. Also, in order to elucidate the maternal metabolic and hormonal factors determining changes in insulin sensitivity, correlations between insulin sensitivity and hormonal factors were performed. To assess inflammation as a potential cause of insulin resistance, we also analyzed inflammatory markers and correlated them with insulin sensitivity.

\section{METHODS AND MATERIALS}

\section{Study participants}

The study was carried out in Central Denmark Region at Aarhus University Hospital. Eight women with GDM were recruited from the outpatient clinic for pregnant women.

Inclusion criteria were women of European decent with GDM, gestational age (GA) between $32+6$ and $36+6$. Exclusion criteria were any chronic illness or medication that could affect insulin sensitivity.

\section{Design}

The study was a longitudinal observational study, in which participants were examined on three occasions. To obtain a measure of both insulin secretion (beta cell function) and insulin sensitivity during the same test, a 1-hour IVGTT followed by a 2-hour HEC, known as the 'Botnia clamp, ${ }^{13}$ was performed. The clamp was performed in late pregnancy (LP) between GA $34+0$ to $36+6$, early post partum (EPP) approximately 2 weeks after delivery and late post partum (LPP) 6 months after delivery.

The three study days were identical as outlined in figure 1. After an overnight fast, the participants rested from 08:00 hours in a quiet, thermoneutral environment. The participants were fasting during the study day and those who were treated with insulin were told not to administer their morning insulin. Intravenous catheters were inserted in a heated dorsal hand vein for sampling of arterialized blood ${ }^{14}$ and in an antecubital vein on the contralateral arm for infusion of glucose, saline and insulin during the examination day. A baseline biochemical profile was obtained at $\mathrm{t}=-15 \mathrm{~min}$, the IVGTT was performed from $\mathrm{t}=0-60 \mathrm{~min}$ and HEC was performed from $\mathrm{t}=60-180 \mathrm{~min}$.

For the IVGTT, a bolus of glucose from a $20 \%$ glucose solution in a dosage of $0.3 \mathrm{~g} / \mathrm{kg}$ was given at $\mathrm{t}=0 \mathrm{~min}$ followed by blood sampling at $\mathrm{t}=0,2,4,6,8$ and $10 \mathrm{~min}$ for estimation of first-phase insulin secretion (FPIS) and C-peptide concentrations. Blood was sampled at $\mathrm{t}=20$, 40 and $60 \mathrm{~min}$ for assessment of second-phase insulin secretion (SPIS) and C-peptide concentrations. FPIS was quantified as the time $\mathrm{t}=0-10 \mathrm{~min}$ and SPIS as the time $\mathrm{t}=10-60$ min incremental area under the curve insulin concentrations. ${ }^{13}$ The clamp was started at $\mathrm{t}=60$ with an insulin infusion rate of $1.0 \mathrm{mU} / \mathrm{kg} / \mathrm{min}$ (Insuman Rapid, Sanofi, France) until $\mathrm{t}=180 \mathrm{~min}$. Plasma glucose was clamped at $5.0 \mathrm{mmol} / \mathrm{L}$ by adjusting the infusion rate of an intravenous infusion of $20 \%$ glucose (SAD, Denmark) according to plasma glucose measurements every $10 \mathrm{~min}$ (Beckmann Instruments, USA). Glucose was given with a carrier infusion of $0.9 \% \mathrm{NaCl}$ and to prevent hypokalemia, $1 \mathrm{mmol} / \mathrm{mL} \mathrm{KCl}$ was added to the glucose infusion. Steady-state serum insulin concentrations were measured at $\mathrm{t}=160,170$ and 180 min during the clamp. Insulin sensitivity was calculated as the mean glucose infusion rates $(\mathrm{mg} / \mathrm{kg} / \mathrm{min})$ during the last $30 \mathrm{~min}$ of the clamp, the M-value. ${ }^{15}$ Insulin sensitivity index (ISI) was calculated as the M-value divided by the steady-state serum insulin concentrations. ${ }^{13}$

\section{Assays}

Creatinine, estimated glomerular filtration rate, electrolytes, cholesterol, triglycerides, hemoglobin and $\mathrm{HbAlc}$ were analyzed immediately after blood sampling by a certified medical laboratory technician. The remaining analyses were performed in batch after completion of all study days: insulin (DAKO, Denmark), C-peptide (ALPCO, USA) and glucagon (Mercodia, Sweden) were analyzed by ELISA. Non-esterified fatty acids (NEFA) were analyzed with a commercial kit (Wako Chemicals, Germany). High-sensitive G reactive protein (HS-CRP, BAM 17072 and MAB 17071, R\&D Systems Europe, UK) was analyzed using an in-house ELISA assay. Adiponectin was analyzed using a commercial time-resolved immunofluorometric assays (TR-IFMAs; Autodelfia, PerkinElmer, Finland). Plasma mannose-binding lectin (MBL) was determined by a TR-IFMA as previously described. ${ }^{16}$ Growth hormone $(\mathrm{GH})$ and insulin-like growth factor-1

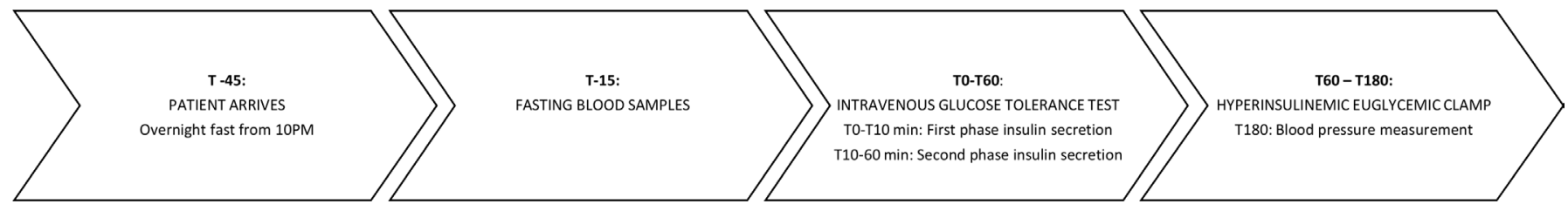

Figure 1 Outline of the study day. 
(IGF-1) were analyzed using a commercial assay based on chemiluminescence technology as previously described (IDS-iSYS platform; Immunodiagnostic Systems, UK) ${ }^{17}$ IGF-binding protein 1 (IGF-BP1) was measured using an in-house TR-IFMA as previously described. ${ }^{18}$ The IGFBP1 assay had intra-assay and inter-assay coefficient of variation $(\mathrm{CVs})$ of $5 \%$ and $8.1 \%$, respectively.

Leptin was determined by a validated in-house TR-IFMA based on commercial reagents (R\&D Systems, UK). ${ }^{19}$ Detection limit was $0.4 \mu \mathrm{g} / \mathrm{L}$, and intra-assay $\mathrm{CV}$ and inter-assay $\mathrm{CV}$ was $<5 \%$ and $<10 \%$, respectively, as previously described. ${ }^{19}$ Fibroblast Growth Factor-21 (FGF-21) was quantified by commercially available monoclonal antibodies (R\&D Systems, DY2539) modified into a TR-IFMA assay as previously described. ${ }^{20}$ Limit of detection was $1 \mathrm{ng} / \mathrm{L}$ and intra-assay and inter-assay CVs were $<6 \%$ and $<10 \%$, respectively.

Plasma cytokines; IL-6 and tumor necrosis factor-alpha $(\mathrm{TNF}-\alpha)$ were measured by magnetic Luminex assays (Pro Human cytokine screening 48-plex (BioRad, USA). Samples were measured in duplicates and analyzed using the BioPlex Manager V.6.0 software (Bio-Rad). Detection limit was $0.34,0.69$ and $1.13 \mathrm{pg} / \mathrm{mL}$, respectively. Notably, IL-10 concentrations were below detection limit in the majority of the samples and thus not reported. The plasma and serum were then transferred to $1.8 \mathrm{~mL}$ tubes and stored at $-80^{\circ} \mathrm{C}$ until analysis.

\section{Statistical analyses}

Results are expressed as mean \pm SE if parametric or median (range) if non-parametric. Repeated-measurement analysis of variance was used to compare the paired data between the visits. Both the repeated measurements for every visit, the repeated measurements for each woman and the missing values were taken into account by using nested random effects in a mixed model. If nonparametric, measurements were analyzed on log scale, and results were back-transformed to obtain relative comparisons. When significant, Bonferroni's post hoc test was applied to adjust for multiple comparisons in order to determine how the visits differed from each other. Model validation was performed by visual inspection of residuals, fitted values and random effect estimates, which did not give cause to reject the model. To measure associations between two continuous variables, we used a Pearson product-moment correlation coefficient.
Table 1 Anthropometrics of the participants

Mean $\pm S E / m e d i a n$ (range) $\mathbf{n}=\mathbf{8}$

\begin{tabular}{ll}
\hline Age (years) & $33.5 \pm 1.25$ \\
\hline Prepregnancy BMI $\left(\mathrm{kg} / \mathrm{m}^{2}\right)$ & $24.7 \pm 0.7$ \\
\hline Parity (P0/P1/P2) & $4 / 3 / 1$ \\
\hline Insulin therapy $(\mathrm{Y} / \mathrm{N})$ & $3 / 5$ \\
\hline Mean daily insulin dose $(\mathrm{n}=3)$ & $10.9 \pm 3.9 \mathrm{IU}$ \\
\hline Exercise weekly (min/week)* & $124 \pm 40$ \\
\hline $\begin{array}{l}\text { Gestational age at visit } 1 \\
\text { (week+day) }\end{array}$ & $35+6(34+0 ; 36+6)$ \\
\hline Days post partum at visit 2 & $1(12 ; 34)$ \\
\hline Days post partum at visit 3 & $192(170 ; 263)$ \\
\hline Fetal birth weight $(\mathrm{g})$ & $3377 \pm 206$ \\
\hline
\end{tabular}

*Self-reported.

BMI, body mass index.

Power calculations were based on the primary end point, insulin sensitivity, expressed as the M-value during the clamp. We wanted to be able to detect a difference $\geq 14 \%$ and based on our previous HEC studies, we set the SD of the M-value at $10 \%$. With a power of $80 \%$ and an $\alpha$-value of $5 \%$, eight subjects had to be included. Statistical significance was defined as $\mathrm{p}<0.05$. All calculations were carried out using STATA V.13.

\section{RESULTS}

Eight women with GDM were included in the study. Table 1 presents anthropometric data from the first visit. The mean age was 33.5 years \pm 1.25 , prepregnancy body mass index (BMI) 24.7 \pm 0.7 and fetal birth weight 3377 $\mathrm{g} \pm 206$. Four of the women were nullipara, three were primipara and one was multiparous (P2). None of the women had polycystic ovarian syndrome (PCOS), but three of the women were treated with small doses of insulin (mean daily dose $=10.9 \pm 3.9 \mathrm{IU}$ ). The median GA at the visit in late pregnancy (LP) was 35 weeks+6 days $(34+0 ; 36+6)$. The EPP and the LPP visit were carried out $16(12 ; 34)$ and $192(170 ; 263)$ days post partum, respectively. All women were breastfeeding EPP, but LPP one had stopped.
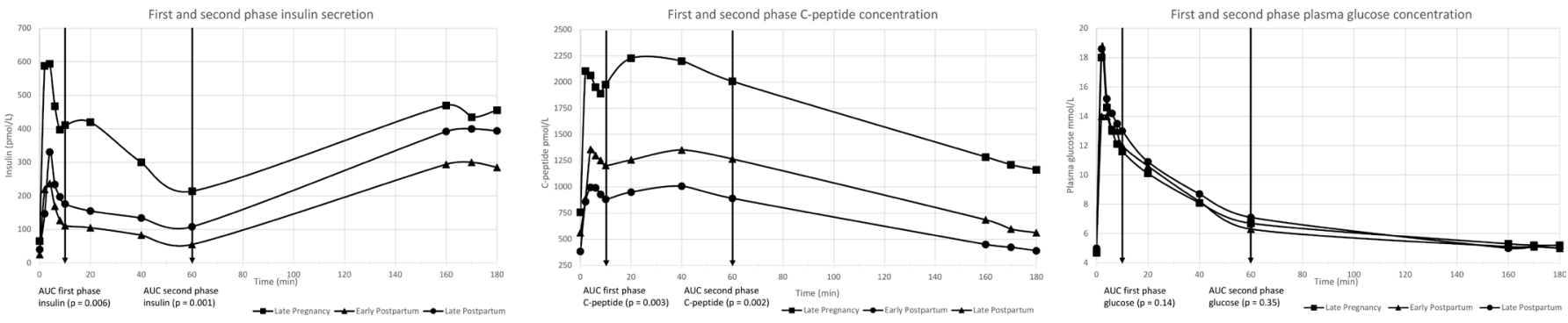

Figure 2 First and second phase secretion of insulin and C-peptide and plasma glucose concentrations. 


\section{Beta cell function}

Figure 2 shows first and second phase insulin secretion and C-peptide and plasma glucose concentrations at every visit. First and second phase insulin secretion were found to be highest in LP, compared with both EPP and LPP $(p<0.001)$. Thus, first phase insulin secretion decreased with $73 \%$ from LP to EPP but was only decreased by $57 \%$ at LPP. The decrease in second phase insulin secretion was $74 \%$ (LP vs EPP) and 50\% (LP vs LPP), respectively. First and second phase concentrations in C-peptide were also highest at LP compared with EPP and LPP $(p<0.001)$ with a decrease in first phase C-peptide of 55\% from LP to EPP and a decrease of $33 \%$ from LP to LPP. The decrease in second phase C-peptide was 56\% (LP vs EPP) and 44\% (LP vs LPP), respectively. Although the concentrations of insulin and C-peptide were lower LP than LPP, the postpartum visits did not differ statistically. First and second phase plasma glucose were the same at all three visits.

\section{Insulin sensitivity}

Insulin sensitivity, expressed by the mean M-value, was lowest LP $\left(\mathrm{M}_{\mathrm{LP}}\right)(1.9 \pm 0.1)$ compared with insulin sensitivity post partum $\left(\mathrm{M}_{\mathrm{EPP}}=3.8 \pm 0.4\right.$ and $\mathrm{M}_{\mathrm{LPP}}=3.8 \pm 0.3$ $(\mathrm{p}<0.001)$. Insulin sensitivity EPP and LPP did not differ from each other $(p=1.0)$ When adjusting for the steady-state serum insulin concentrations during the clamp, insulin sensitivity expressed as the ISI differed at all three visits: $\operatorname{ISI}_{\mathrm{LP}}=0.03 \pm 0.004, \mathrm{ISI}_{\mathrm{EPP}}=0.09 \pm 0.008$ and ISI $_{\text {LPP }}=0.07 \pm 0.008$ ) (table 2 and figure 3 ), with the lowest insulin sensitivity in late pregnancy, the highest insulin sensitivity early post partum and a subsequent decrease in insulin sensitivity late post partum.

\section{Metabolic, hormonal and inflammatory markers}

Table 2 shows all metabolic, hormonal and inflammatory markers of all the participants at each visit. Cholesterol and high-density lipoprotein (HDL) were lowest LPP $(\mathrm{p}<0.03)$, whereas low-density lipoprotein (LDL) and triglyceride were highest EPP and LP, respectively $(p=0.001)$. Glucagon decreased through all three visits $(\mathrm{p}<0.0001)$. IGF-1 and IGF-BP1 were highest LP compared with the two other visits and decreased post partum. Pituitary GH was lowest LP but only reached the level of statistical difference when compared with LPP $(\mathrm{p}<0.001)$.

Leptin and MBL concentrations were highest LP, but the differences only reached the level of statistical difference between LP and EPP (leptin: $\mathrm{p}=0.002$, MBL: $\mathrm{p}=0.04$ ). We observed no difference in HbAlc, plasma glucose, creatinine, NEFA, thyroid-stimulating hormone, adiponectin, FGF-21, HS-CRP, IL-6 or TNF- $\alpha$, comparing the three visits.

At LP and LPP, we found a negative correlation between insulin sensitivity expressed by the M-value and leptin concentration, LP: $\mathrm{r}=-0.72, \mathrm{p}=0.043$ and LPP: $\mathrm{r}=-0.77$, $\mathrm{p}=0.04$. The same association was not found at EPP. In addition, there was a positive correlation between the M-value and IGF-1 at EPP: $r=0.88, p=0.02$. For glucagon we found a negative correlation with the M-value at LPP: $\mathrm{r}=-0.78, \mathrm{p}=0.04$. We found no associations between insulin sensitivity and adiponectin, IGF-BP1, HS-CRP, GH, FGF-21, MBL, IL-6, TNF- $\alpha$, cholesterol, HDL, LDL, triglyceride or NEFA at any visits (table 3 ).

\section{DISCUSSION}

\section{Insulin secretion}

During pregnancy, there is an increase in beta cell mass through proliferation and hypertrophy of the beta cells ${ }^{21}$ and the adaptations seem to occur in the beta cells prior to the onset of insulin resistance. The inability to produce sufficient insulin can be due to the lipotoxicity and glucotoxicity that are prominent in type 2 diabetes and GDM and a possible cause of the beta cell dysfunction. ${ }^{22}$ In our study, we found that both first and second phase insulin and C-peptide concentrations were higher in late pregnancy compared with 2 weeks and 6 months post partum. The insulin responses post partum were comparable, but the C-peptide levels were higher 6 months post partum, which is in accordance with the decrease in insulin sensitivity that we find 6 months post partum. Catalano et $a t^{23}$ examined insulin secretion by an IVGTT in seven women with GDM and in eight pregnant women with normal glucose tolerance (NGT) before conception, at 12-14 weeks and at 34-36week's gestation and showed that there was a significant $60 \%$ increase in first-phase insulin response to intravenous glucose infusion and a $130 \%$ increase in second phase insulin response with advancing gestation in obese women with NGT, whereas in lean women with NGT, there was a 200\%-250\% increase in insulin response to the same glucose stimulus. Women with GDM had significantly greater second phase response compared with the control group but there was no difference in the first phase insulin response. ${ }^{23}$ There are, to our knowledge, no previous studies that have performed IVGTTs in women with GDM 6 months post partum.

In a study by Waters $e t a l,{ }^{9}$ insulin secretion was estimated by an OGTT in late pregnancy, 1-5 days after delivery and 6-12 weeks post partum. They reported improvement in insulin production within the first few days post partum. The improvement in insulin production compared with late pregnancy persisted after 6-12 weeks. In our study, insulin secretion, although not significantly, was increased LPP compared with EPP. This could indicate a beginning compensation for the slowly increasing insulin resistance.

\section{Insulin sensitivity}

This study reports measurements of beta cell function by an IVGTT combined with a HEC at three important time points: late in pregnancy between GA $34+0$ to $36+6$ (LP), approximately 2 weeks post partum (EPP) and 6 months post partum (LPP). Insulin sensitivity improved twofold to threefold immediately after delivery, but already after 6 months postpartum 
Table 2 Metabolic, hormonal and inflammatory parameters

\begin{tabular}{|c|c|c|c|c|}
\hline & Late pregnancy $n=8$ & Early post partum $n=6$ & Late post partum $n=7$ & $P$ value \\
\hline \multicolumn{5}{|l|}{ Metabolic parameters } \\
\hline M value & $1.9 \pm 0.1^{a}$ & $3.8 \pm 0.4^{b}$ & $3.8 \pm 0.3^{b}$ & $<0.0001$ \\
\hline ISI & $0.03 \pm 0.004^{a}$ & $0.09 \pm 0.01^{b}$ & $0.07 \pm 0.008^{c}$ & $<0.0001$ \\
\hline Weight (kg) & $79.5 \pm 3.6^{\mathrm{a}}$ & $71.8 \pm 4.5^{\mathrm{b}}$ & $68.9 \pm 4.2^{c}$ & $<0.0001$ \\
\hline BMI & $28.3 \pm 0.9^{a}$ & $25.3 \pm 0.7^{b}$ & $24.9 \pm 1.2^{c}$ & $<0.0001$ \\
\hline Systolic blood pressure & $119 \pm 3$ & $112 \pm 3^{\mathrm{a}}$ & $121 \pm 4^{b}$ & 0.04 \\
\hline Diastolic blood pressure & $71 \pm 3$ & $68 \pm 4$ & $76 \pm 5$ & NS \\
\hline $\mathrm{HbA} 1 \mathrm{c} \mathrm{mmol} / \mathrm{mol}$ & $36 \pm 1.7$ & $38 \pm 2$ & $37 \pm 2$ & NS \\
\hline $\mathrm{HbA1c} \%$ & $5.4+0.2$ & $5.6+0.2$ & $5.5+0.2$ & NS \\
\hline Plasma glucose & $5.2 \pm 0.1$ & $5.1 \pm 0.1$ & $5.0 \pm 0.1$ & NS \\
\hline Creatinine & $52.8 \pm 4$ & $61.7 \pm 4$ & $56.5 \pm 4$ & NS \\
\hline Cholesterol & $5.7 \pm 0.3^{\mathrm{a}}$ & $5.8 \pm 0.4^{\mathrm{a}}$ & $4.4 \pm 0.3^{b}$ & $<0.0001$ \\
\hline $\mathrm{HDL}$ & $1.8 \pm 0.2^{\mathrm{a}}$ & $1.6 \pm 0.2^{\mathrm{a}}$ & $1.3 \pm 0.2^{b}$ & $<0.0001$ \\
\hline LDL & $2.8 \pm 0.3^{\mathrm{a}}$ & $3.7 \pm 0.3^{b}$ & $2.6 \pm 0.2^{\mathrm{a}}$ & $<0.0001$ \\
\hline Triglyceride & $2.5 \pm 0.3^{a}$ & $1.1 \pm 0.1^{b}$ & $1 \pm 0.2^{\mathrm{b}}$ & $<0.0001$ \\
\hline eGFR & $>90$ & $>90$ & $>90$ & \\
\hline Sodium & $137 \pm 0.3^{\mathrm{a}}$ & $140 \pm 0.3^{b}$ & $140 \pm 0.4^{b}$ & $<0.0001$ \\
\hline Potassium & $3.7 \pm 0.1^{\mathrm{a}}$ & $4 \pm 0.1^{b}$ & $3.9 \pm 0.1$ & 0.01 \\
\hline NEFA & $1.2 \pm 0.2$ & $1 \pm 0.1$ & $1.1 \pm 0.1$ & NS \\
\hline \multicolumn{5}{|l|}{ Hormonal parameters } \\
\hline Insulin & $65.4 \pm 10^{a}$ & $25 \pm 4^{b}$ & $40 \pm 5.4^{b}$ & 0.0002 \\
\hline Glucagon & $124 \pm 9.3^{a}$ & $112 \pm 9.2^{b}$ & $101 \pm 9.4^{c}$ & $<0.0001$ \\
\hline C-peptide & $758 \pm 97^{a}$ & $384 \pm 26^{b}$ & $562 \pm 61^{c}$ & $<0.0001$ \\
\hline $\mathrm{TSH}$ & $2 \pm 0.3$ & $1.0 \pm 0.1$ & $2.6 \pm 0.9$ & NS \\
\hline Adiponectin & $8.9 \pm 1.7$ & $8.4 \pm 2.6$ & $9.1 \pm 1.5$ & NS \\
\hline IGF-1 & $267 \pm 29.7^{\mathrm{a}}$ & $145 \pm 14.9^{b}$ & $185 \pm 12.1^{b}$ & $<0.0001$ \\
\hline IGF-BP1 & $86 \pm 9.9^{a}$ & $41 \pm 5.4^{\mathrm{b}}$ & $21 \pm 2.8^{b}$ & $<0.0001$ \\
\hline $\mathrm{GH}$ & $0.3 \pm 0.2^{\mathrm{a}}$ & $1.6 \pm 0.8$ & $2.5 \pm 0.5^{b}$ & 0.002 \\
\hline Leptin & $32.9 \pm 7.3^{\mathrm{a}}$ & $17.3 \pm 2.2^{b}$ & $21.3 \pm 6.7$ & 0.003 \\
\hline FGF-21 & $297 \pm 66.6$ & $362 \pm 109.1$ & $309 \pm 86.4$ & NS \\
\hline \multicolumn{5}{|l|}{ Inflammatory parameters } \\
\hline HS-CRP & $6.6 \pm 3.8$ & $5.3 \pm 2.5$ & $1.9 \pm 1.3$ & NS \\
\hline MBL & $1948 \pm 78^{a}$ & $989 \pm 342^{b}$ & $1238 \pm 405$ & 0.03 \\
\hline IL-6 & $1.4 \pm 0.3$ & $1.8 \pm 0.8$ & $1.1 \pm 0.4$ & NS \\
\hline TNF- $\alpha$ & $12.6 \pm 1.2$ & $10.3 \pm 0.9$ & $11.1 \pm 1.4$ & NS \\
\hline
\end{tabular}

Variables are summarized by mean \pm SE.

${ }^{a, b, c} \mathrm{P}<0.05$ indicates statistical significant difference between the respective visits, eg, for the M-value, we found statistically significant difference between visit 1 and visit 2 and between visit 1 and visit 3 but no statistically significant difference between visit 2 and visit 3 . BMI, body mass index; eGFR, estimated glomerular filtration rate; FGF-21, Fibroblast Growth Factor-21; GH, growth hormone; HbA1c, hemoglobin A1c; HDL, high-density lipoprotein; HS-CRP, high-sensitive C reactive protein; IGF-1, insulin-like growth factor-1; IGF-BP1, IGF-binding protein 1; IL, interleukin; ISI, insulin sensitivity index; LDL, low-density lipoprotein; MBL, mannose-binding lectin; NEFA, nonesterified fatty acid; NS, not significant; TNF, tumor necrosis factor; TSH, thyroid-stimulating hormone.

insulin sensitivity decreased compared with 2 weeks after delivery. As insulin levels and C-peptide levels were different on the three study days, we corrected for insulin levels and used ISI as the most correct and valid measure of insulin sensitivity.
Kirwan $e t a l^{10}$ and Friedman $e t a l^{11}$ studied the changes in insulin sensitivity post partum by performing a HEC in women with $\mathrm{NGT}^{10}$ and in women with $\mathrm{GDM}^{11}$ in late pregnancy (week 30-36) and 1 year post partum. Insulin sensitivity improved $74 \%$ from late pregnancy to 1 year 


\section{4,5}

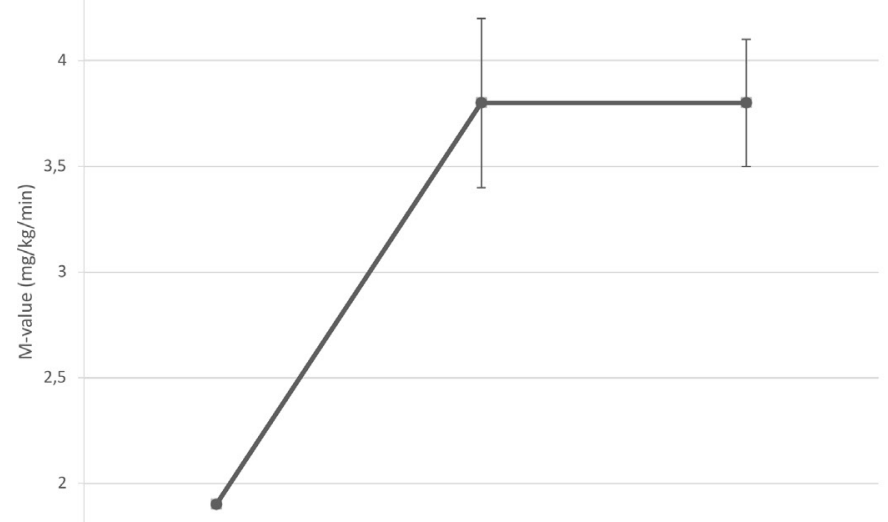

1,5

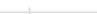

Early Postpartum

Late Postpartum

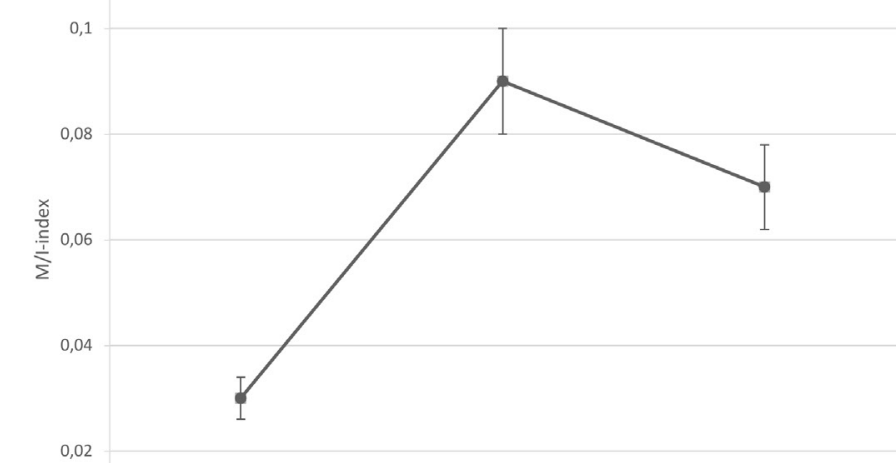

Late Pregnancy

alue and insulin sensitivity index (ISI).

post partum in the women with NGT but there was no significant improvement in insulin sensitivity in the women with GDM 1 year post partum. In a study by Ryan et $a l,{ }^{12}$ insulin sensitivity was assessed by a HEC in late pregnancy and again 3 days post partum in women with GDM and NGT, respectively, and found that insulin resistance was ameliorated shortly after delivery. The postpartum values did not differ significantly from the values obtained from a non-diabetic, non-pregnant group, but only four women were included in the postpartum studies (two women with GDM and two women with NGT). ${ }^{12}$ In the study by Waters $e t a l,{ }^{9}$ the authors reported that delivery was associated with an improvement in insulin sensitivity within the first few days, but after 6-12 weeks, a slight deterioration was found. This supports the findings in our study and indicates that the resurgence of insulin resistance might start before the 6 months we used in our study.

\begin{tabular}{|c|c|c|c|c|c|c|}
\hline & \multicolumn{2}{|c|}{ Late pregnancy } & \multicolumn{2}{|c|}{ Early post partum } & \multicolumn{2}{|c|}{ Late post partum } \\
\hline & PCV & $P$ value & PCV & $P$ value & PCV & P value \\
\hline Leptin & -0.72 & $0.043^{*}$ & -0.37 & 0.47 & -0.77 & $0.04^{\star}$ \\
\hline IGF-1 & 0.63 & 0.09 & 0.88 & $0.02^{\star}$ & -0.37 & 0.4 \\
\hline Glucagon & -0.40 & 0.38 & -0.29 & 0.63 & -0.78 & $0.04^{*}$ \\
\hline Adiponectin & 0.28 & 0.5 & 0.66 & 0.16 & 0.47 & 0.29 \\
\hline IGF-BP1 & 0.06 & 0.89 & 0.44 & 0.38 & 0.57 & 0.18 \\
\hline HS-CRP & 0.07 & 0.87 & -0.74 & 0.09 & -0.68 & 0.09 \\
\hline $\mathrm{GH}$ & 0.23 & 0.59 & 0.13 & 0.8 & -0.12 & 0.79 \\
\hline FGF-21 & -0.09 & 0.84 & 0.27 & 0.6 & 0.24 & 0.60 \\
\hline MBL & 0.15 & 0.73 & 0.79 & 0.06 & -0.29 & 0.53 \\
\hline IL-6 & 0.22 & 0.60 & -0.58 & 0.22 & -0.58 & 0.17 \\
\hline TNF- $\alpha$ & 0.22 & 0.61 & 0.00 & 0.99 & 0.09 & 0.85 \\
\hline Cholesterol & -0.51 & 0.2 & 0.28 & 0.59 & 0.45 & 0.31 \\
\hline $\mathrm{HDL}$ & -0.17 & 0.7 & 0.55 & 0.26 & 0.42 & 0.35 \\
\hline LDL & -0.46 & 0.26 & 0.01 & 0.97 & 0.17 & 0.71 \\
\hline Triglyceride & 0.07 & 0.88 & 0.15 & 0.77 & 0.60 & 0.15 \\
\hline NEFA & -0.07 & 0.86 & -0.78 & 0.07 & 0.36 & 0.43 \\
\hline
\end{tabular}

A Pearson's product-moment correlation was used to examine the relationship between the M-value and selected interesting hormones, lipids and cytokines.

${ }^{*} \mathrm{P}<0.05$ was considered significant.

FGF-21, Fibroblast Growth Factor-21; GH, growth hormone; HDL, high-density lipoprotein; HS-CRP, high-sensitive C reactive protein; IGF1, insulin-like growth factor-1; IGF-BP1, IGF-binding protein 1; IL, interleukin; LDL, low-density lipoprotein; MBL, mannose-binding lectin; NEFA, non-esterified fatty acid; PCV, pearson's correlation value; TNF, tumor necrosis factor. 
The level of insulin resistance in our study is striking. Late in pregnancy the M-value was $1.9 \mathrm{mg} / \mathrm{kg} / \mathrm{min}$, compared with $2.4 \mathrm{mg} / \mathrm{kg} / \mathrm{min}$ in the seven women with GDM, examined in the study by Catalano $e t$ al at the same insulin infusion..$^{23}$ Moreover, the M-value was $3.8 \mathrm{mg} /$ $\mathrm{kg} / \mathrm{min}$ post partum in our study, compared with the prepregnancy M-value of $5.4 \mathrm{mg} / \mathrm{kg} / \mathrm{min}$ in the study by Catalano et al.

Hjerrild $e t a l^{24}$ examined insulin sensitivity in healthy, non-pregnant women at the same age (33 \pm 5 years) and BMI $\left(24.5 \mathrm{~kg} / \mathrm{m}^{2}\right)$ and at the same insulin dose $(1.0 \mathrm{mU} /$ $\mathrm{kg} / \mathrm{min}$ ) as in our study and found, that their M-value was $8.9 \mathrm{mg} / \mathrm{kg} / \mathrm{min}$, underlining that the women in our study are very insulin resistant, although they do not present with diabetes post partum. This illustrates that women who develop GDM, compared with women with NGT, have an impaired glucose metabolism both before, during and after pregnancy, why they are more prone to develop type 2 diabetes in the years following pregnancy.

\section{Hormonal and inflammatory markers}

In the present study, we found that leptin levels decreased shortly after delivery but increased again 6 months post partum. Highman et $a l^{25}$ evaluated the longitudinal changes in maternal serum leptin concentrations before pregnancy, in early pregnancy (12-14 weeks) and in late pregnancy (34-36 weeks) in 10 women and reported that leptin levels increased with $66 \%$ from prepregnancy $(25.4 \pm 19.9)$ to late pregnancy $(38.4 \pm 27.3)$ and found a positive correlation between leptin and body fat. In our study, we found leptin levels late in pregnancy comparable to those in the study by Highman et al $(32.9 \pm 7.3)$ and that leptin levels almost halved post partum (17.3 \pm 2.2$)$ and were significantly negatively correlated with insulin sensitivity, supporting that leptin play a role in insulin resistance in pregnancy. It is well known that leptin is produced by adipocytes why the correlation between fat mass and leptin is strongly positive. ${ }^{26}$ Unfortunately, we were not able to obtain fat mass estimates from the participants and therefore this association remains unexplored in our study.

Our finding that leptin is negatively correlated with insulin sensitivity is in line with the findings of Kirwan et $a l,{ }^{27}$ who performed a study including 5 women with GDM and 10 women with NGT where HEC was carried out before pregnancy, early in pregnancy (GA 12-14 weeks) and in late pregnancy (GA 34-36 weeks). Insulin sensitivity was here strongly negatively associated with leptin levels late in pregnancy.

McIntyre $e t a t^{28}$ also describe a negative correlation between leptin and insulin sensitivity based on IS-OGTT and IS-HOMA in late pregnancy in pregnant women with NGT. Altogether, McIntyre $e t a l^{28}$ conclude that the variance in maternal insulin sensitivity in pregnancy is associated with leptin and the GH axis as IGF-BP1 was positively correlated with insulin sensitivity. This is in accordance with our study, as we found a positive correlation between IGF-1 and insulin sensitivity shortly after delivery. IGF-I has structural homology with insulin and a study done by Friedrich $e t a l^{29}$ found a U-shaped association between IGF-1 and insulin resistance as both low and high levels of IGF-1 were related to insulin resistance. The mechanism of this complex relationship remains to be fully understood.

In parallel with other studies, we found that MBL levels were very high in late pregnancy with a substantial decrease shortly after delivery. According to van de Geijn $e t a l,{ }^{30} \mathrm{MBL}$ increases already in the first trimester of pregnancy up to $140 \%$ of the baseline level with a sharp decrease after delivery. The authors hypothesize that the rise in MBL contributes to a normal placentation and pregnancy, and that it might reflect a shift from adaptive to innate immunity in pregnancy, ameliorating certain autoimmune diseases. We examined the associations with MBL and insulin sensitivity, as previous studies have found that serum MBL levels are positively related to insulin sensitivity in women with PCOS. ${ }^{31}$ We did however, not find a correlation between insulin sensitivity and MBL in our study, which could be due to lack of power. Interestingly, glucagon decreased significantly through all three visits and we found a negative correlation between glucagon and the M-value at visit 3. Beis $e t a l^{32}$ found that plasma glucagon levels were higher $(\mathrm{p}<0.05)$ in women with GDM compared with normal pregnant women at baseline and after an OGTT. Another recent study also found an impaired glucagon suppression in patients with GDM when performing a $75 \mathrm{~g}$ OGTT during mid-gestation. ${ }^{33}$ Thus, the absence of suppressibility of glucagon in women with GDM might be involved in the pathogenesis of glucose intolerance in women with $\mathrm{GDM},{ }^{32}$ but its role still remains to be fully elucidated. $^{33}$

Regarding inflammatory markers, Kirwan et $a l^{27}$ also measured TNF- $\alpha$ in the before mentioned study and found that insulin sensitivity was negatively associated with TNF- $\alpha$ and was found to be the best predictor of insulin sensitivity in pregnant women. In the current study, we did however not find any increase in TNF- $\alpha$ and no correlations between TNF- $\alpha$ and insulin sensitivity. We did not find changes in the levels of TNF- $\alpha$, IL-6 or HS-CRP when comparing the three visits either. This is in contrast to Christian and Porter, ${ }^{34}$ who measured IL-6, TNF- $\alpha$ and CRP in pregnant, non-diabetic women with a $\mathrm{BMI}>18.5 \mathrm{~kg} / \mathrm{m}^{2}$ in the first, second and third trimester and post partum and found that IL- 6 and TNF- $\alpha$ increased during pregnancy with a further increase post partum. CRP, on the other hand, decreased during the period, whereas we were unable to detect a difference in HS-CRP.

\section{Strengths and limitations}

The obvious strength of our study is the methods used to assess insulin secretion and insulin sensitivity. The HEC is widely acknowledged as the gold standard for evaluating insulin sensitivity. It is both reproducible and sensitive and by using an IVGTT to assess insulin secretion, the potential impact of the incretin hormones on insulin secretion 
is eliminated. In addition, our study contributes with new knowledge on how insulin sensitivity and insulin secretion alter 6 months post partum in women with GDM, as previous studies have evaluated these parameters a few days or a year after delivery.

The small sample size in our study could be considered a weakness. Nevertheless, studies similar to ours examining women with GDM with labor-intensive methods as IVGTT and HEC have also only included a small number of participants (Ryan n=2 (GDM), Kirwan $n=5$ (GDM), Schmitz $n=6$ (type 1 diabetes)). ${ }^{12} 2735$ As the methods used have a high degree of precision and reproducibility only few participants are needed to capture differences, as predicted by our power calculation. The power calculations are solely based on the primary end point, insulin sensitivity and not the biochemical and hormonal parameters. However, previous studies evaluating hormonal correlations during pregnancy, also report small numbers of participants, ${ }^{25}$ as recruitment of pregnant participants to laborious experiments can be challenging.

\section{CONCLUSION}

In this study, we show that insulin sensitivity in women with GDM already starts to deteriorate within 6 months post partum. This underlines the importance of increased focus on the profound risk of developing type 2 diabetes after GDM and warrants initiatives shortly after delivery including dietary, lifestyle and pharmacological interventions aimed at preventing or delaying type 2 diabetes.

Acknowledgements The authors would like to thank laboratory technicians Annette Mengel, Hanne Petersen and Lisa Buus for invaluable assistance with biochemical analyses and assistance during the study day. The authors would also like to thank the women and their families who participated in the study.

Contributors PO, UK and NM conceived the study, GOS, JF and PO recruited the participants, GOS, UK, JF and PO designed and planned the experiments, GOS and UK coordinated the work and carried out the experiments. GOS, UK and SK collected data. GOS and UK analyzed the data and wrote the manuscript. NM, JF and PO contributed to the discussion. All authors provided critical feedback on the design, experiments, analyses and manuscript.

Funding The study was supported by donations from 'Johan Boserup og Lise Boserups Legat' and The Augustinus Foundation. GOS and UK are supported by the Danish Diabetes Academy, funded by the Novo Nordisk Foundation. PO received financial support from the Novo Nordisk Foundation.

Disclaimer statement The funding sources had no role in the study design, inclusion process, data analysis or statistical considerations or in the writing of this report.

\section{Competing interests None declared.}

Patient consent for publication Not required.

Ethics approval The study was approved by the Regional Ethical Committee and was conducted in accordance with the Helsinki Declaration. The purpose of the study was explained to all the participants before written consent was obtained.

Provenance and peer review Not commissioned; externally peer reviewed.

Data availability statement Data are available on reasonable request, pending approval from the relevant ethical committees. The authors confirm that, for approved reasons, some access restrictions apply to the datasets generated during and/or analyzed during the current study underlying the findings.

Open access This is an open access article distributed in accordance with the Creative Commons Attribution Non Commercial (CC BY-NC 4.0) license, which permits others to distribute, remix, adapt, build upon this work non-commercially, and license their derivative works on different terms, provided the original work is properly cited, appropriate credit is given, any changes made indicated, and the use is non-commercial. See: http://creativecommons.org/licenses/by-nc/4.0/.

\section{ORCID iDs}

Gitte Oeskov Skajaa http://orcid.org/0000-0003-3097-4175

Jens Fuglsang http://orcid.org/0000-0002-0181-1986

\section{REFERENCES}

1 Catalano PM. Trying to understand gestational diabetes. Diabet Med 2014;31:273-81.

2 Catalano PM, Tyzbir ED, Roman NM, et al. Longitudinal changes in insulin release and insulin resistance in nonobese pregnant women. Am J Obstet Gynecol 1991;165:1667-72.

3 Mclntyre HD, Catalano P, Zhang C, et al. Gestational diabetes mellitus. Nat Rev Dis Primers 2019:5:1-19.

4 Bellamy L, Casas J-P, Hingorani AD, et al. Type 2 diabetes mellitus after gestational diabetes: a systematic review and meta-analysis. Lancet 2009;373:1773-9.

5 Lauenborg J, Mathiesen E, Hansen T, et al. The prevalence of the metabolic syndrome in a danish population of women with previous gestational diabetes mellitus is three-fold higher than in the general population. J Clin Endocrinol Metab 2005;90:4004-10.

6 American Diabetes Association. Management of diabetes in pregnancy: standards of medical care in diabetes. Diabetes Care 2019;42:S165-72.

7 Werner EF, Has P, Tarabulsi G, et al. Early postpartum glucose testing in women with gestational diabetes mellitus. Am J Perinatol 2016;33:697-9.

8 Schaefer-Graf UM, Klavehn S, Hartmann R, et al. How do we reduce the number of cases of missed postpartum diabetes in women with recent gestational diabetes mellitus? Diabetes Care 2009;32:1960-4.

9 Waters TP, Kim SY, Sharma AJ, et al. Longitudinal changes in glucose metabolism in women with gestational diabetes, from late pregnancy to the postpartum period. Diabetologia 2020;63:385-94.

10 Kirwan JP, Varastehpour A, Jing M, et al. Reversal of insulin resistance postpartum is linked to enhanced skeletal muscle insulin signaling. J Clin Endocrinol Metab 2004;89:4678-84.

11 Friedman JE, Kirwan JP, Jing M, et al. Increased skeletal muscle tumor necrosis factor-alpha and impaired insulin signaling persist in obese women with gestational diabetes mellitus 1 year postpartum. Diabetes 2008;57:606-13.

12 Ryan EA, O'Sullivan MJ, Skyler JS. Insulin action during pregnancy. Studies with the euglycemic clamp technique. Diabetes 1985;34:380-9.

13 Tripathy D, Wessman Y, Gullström M, et al. Importance of obtaining independent measures of insulin secretion and insulin sensitivity during the same test: results with the Botnia clamp. Diabetes Care 2003:26:1395-401.

14 Brooks DC, Black PR, Arcangeli MA, et al. The heated dorsal hand vein: an alternative arterial sampling site. JPEN J Parenter Enteral Nutr 1989;13:102-5.

15 DeFronzo RA, Tobin JD, Andres R. Glucose clamp technique: a method for quantifying insulin secretion and resistance. Am J Physiol 1979;237:E214.

16 Degn SE, Jensen L, Gál P, et al. Biological variations of MASP-3 and MAp44, two splice products of the MASP1 gene involved in regulation of the complement system. $J$ Immunol Methods 2010;361:37-50.

17 Clemmons DR. Clinical laboratory indices in the treatment of acromegaly. Clin Chim Acta 2011;412:403-9.

18 Reinhard M, Frystyk J, Jespersen B, et al. Effect of hyperinsulinemia during hemodialysis on the insulin-like growth factor system and inflammatory biomarkers: a randomized open-label crossover study. BMC Nephrol 2013;14:80.

19 Asferg C, Møgelvang R, Flyvbjerg A, et al. Leptin, not adiponectin, predicts hypertension in the Copenhagen city heart study. $\mathrm{Am} \mathrm{J}$ Hypertens 2010;23:327-33.

20 Lauritzen ES, Rittig N, Bach E, et al. Lps infusion suppresses serum FGF21 levels in healthy adult volunteers. Endocr Connect 2017;6:39-43.

21 Moyce B, Dolinsky V. Maternal $\beta$-cell adaptations in pregnancy and placental signalling: implications for gestational diabetes. Int $\mathrm{J} \mathrm{Mol}$ Sci 2018;19:3467.

22 Sharma RB, Alonso LC. Lipotoxicity in the pancreatic beta cell: not just survival and function, but proliferation as well? Curr Diab Rep 2014;:14:492.

23 Catalano PM, Huston L, Amini SB, et al. Longitudinal changes in glucose metabolism during pregnancy in obese women with normal 
glucose tolerance and gestational diabetes mellitus. Am J Obstet Gynecol 1999;180:903-16.

24 Hjerrild BE, Holst JJ, Juhl CB, et al. Delayed $\beta$-cell response and glucose intolerance in young women with Turner syndrome. $B M C$ Endocr Disord 2011;11:6.

25 Highman TJ, Friedman JE, Huston LP, et al. Longitudinal changes in maternal serum leptin concentrations, body composition, and resting metabolic rate in pregnancy. Am J Obstet Gynecol 1998;178:1010-5.

26 Zhou Y, Rui L. Leptin signaling and leptin resistance. Front Med 2013;7:207-22.

27 Kirwan JP, Hauguel-De Mouzon S, Lepercq J, et al. Tnf-Alpha is a predictor of insulin resistance in human pregnancy. Diabetes 2002;51:2207-13.

28 McIntyre HD, Chang AM, Callaway LK, et al. Hormonal and metabolic factors associated with variations in insulin sensitivity in human pregnancy. Diabetes Care 2010;33:356-60.

29 Friedrich N, Thuesen B, Jørgensen T, et al. The association between IGF-I and insulin resistance: a general population study in Danish adults. Diabetes Care 2012;35:768-73.
30 van de Geijn FE, Roos A, de Man YA, et al. Mannose-binding lectin levels during pregnancy: a longitudinal study. Hum Reprod 2007;22:362-71.

31 Kowalska I, Fernandez-Real JM, Straczkowski M, et al. Insulin resistance is associated with decreased circulating mannan-binding lectin concentrations in women with polycystic ovary syndrome. Diabetes Care 2008;31:e20.

32 Beis C, Grigorakis SI, Philippou G, et al. Lack of suppression of plasma glucagon levels in late pregnancy persists postpartum only in women with previous gestational diabetes mellitus. Acta Diabetol 2005;42:31-5.

33 Horie I, Haraguchi A, Ito A, et al. Impaired early-phase suppression of glucagon secretion after glucose load is associated with insulin requirement during pregnancy in gestational diabetes. $J$ Diabetes Investig 2020;11:232-40.

34 Christian LM, Porter K. Longitudinal changes in serum proinflammatory markers across pregnancy and postpartum: effects of maternal body mass index. Cytokine 2014;70:134-40.

35 Schmitz O, Klebe J, Møller J, et al. In vivo insulin action in type 1 (insulin-dependent) diabetic pregnant women as assessed by the insulin clamp technique. J Clin Endocrinol Metab 1985;61:877-81. 